Journal of Energy and
Environmental Sustainability (ISEES)
Journal homepage : www.jees.in

\title{
Performance of Alum \& Polyaluminum Chloride as Efficient Coagulants for Fluoride Removal in Batch and Continuous Reactors
}

\author{
Swati Dubey ${ }^{1}$, Madhu Agarwal $^{*}$, Akhilendra Bhushan Gupta ${ }^{3}$, Yogendra Solanki ${ }^{4}$ \\ ${ }^{1}$ Department of Chemical Engineering, Malaviya National Institute of Technology, Jaipur, India 302017 \\ ${ }^{* 2}$ Department of Chemical Engineering, Malaviya National Institute of Technology, Jaipur, India 302017 \\ ${ }^{3}$ Department of Civil Engineering, Malaviya National Institute of Technology, Jaipur, India 302017 \\ ${ }^{4}$ Department of Chemical Engineering, Malaviya National Institute of Technology, Jaipur, India 302017
}

\section{A R T I C L E I N F O}

Received : 31 January 2018

Revised : 19 March 2018

Accepted : 10 April 2018

Keywords:

Fluoride, alum, polyaluminum chloride, batch, continuous

Nomenclature

PACl- Poly aluminum chloride

Alum- Aluminum sulphate

\begin{abstract}
A B S T R A C T
In this study, performance of alum and polyaluminum chloride(PACl) for fluoride removal has been compared in batch and continuous modes. Experiments were performed to determine the optimum doses of coagulant for bringing the fluoride $(<1.5 \mathrm{ppm})$ and aluminum $(0.2 \mathrm{ppm})$ within acceptable limits. The residual fluoride was found to be higher in case of alum as compared to $\mathrm{PACl}$ representing less efficient settling of suspensions, primarily comprise of alumino-fluoro complexes. In addition to this, water treated with $\mathrm{PACl}$ contains relatively low soluble salts compared to alum \& also requires lesser lime for $\mathrm{pH}$ compensation due to its lower acidity. It was also observed that the $\mathrm{PACl}$ treated water contains less residual aluminium $(0.34 \mathrm{ppm})$ compared to alum $(0.46 \mathrm{ppm})$ when initial fluoride concentration of water was $4 \mathrm{ppm}$. In batch mode, residual Al was found to be $0.182 \mathrm{ppm}$ (alum) \& $0.143 \mathrm{ppm}(\mathrm{PACl})$, after subsequent microfiltration which conform to the Al standards in defluoridated water.
\end{abstract}

\section{Introduction}

Exposure to fluoride through drinking water above the permissible limit causes severe dental and skeletal fluorosis (Kaseva, 2006). Skeletal Fluorosis can cause pain and stiffness in joints as well as deformities such as crippling, kyphosis, and genu varum. The World Health Organization recommends an upper limit of $1.5 \mathrm{mg} / \mathrm{L}$ for fluoride in drinking water (Gorchev \& Ozolins, 2011).

Various processes such as coagulation, precipitation, adsorption, ion exchange electrocoagulation, reverse osmosis, and nano-ûltration have been adopted for deûuoridation of drinking water (Dubey et al., 2017a, Agarwal et al., 2017). The techniques used for defluoridation of water, are mainly dependent on either adsorption or precipitation. Activated alumina process based on adsorption and widely used in the field has the major disadvantage of leaving residual aluminium in excess of $0.2 \mathrm{mg} / \mathrm{L}$ in the treated water. The essential requirement of electricity and exorbitant cost of RO process make it unsuitable for community supplies in developing countries like Africa, India etc. and it cannot compete economically with general field processes used for defluoridation (Waghmare et al., 2015). Electrocoagulation is an effective process for defluoridation but when it is operated in a continuous mode to serve relatively large communities, there is a problem of high turbidity in the treated water (Hu et al., 2003). The Nalgonda Defluoridation Technique which is based on coagulation is considered to be the most economical and simple method for bringing the fluoride content to acceptable limit in drinking water and is reported to have high removal efficiency (He et al.,
2016). Aluminium salts such as sulphates or chlorides, lime and bleaching coagulants are added to the raw water in a batch process followed by rapid mixing, flocculation, sedimentation and filtration. Lime facilitates complete hydrolysis of alum forming dense aluminium hydroxide flocs for rapid settling while retaining a minimum residual alkalinity of 1 to 2 meq $/ 1$ and $\mathrm{pH}$ between 6.5 and 8.5 in treated water (Dubey et al., 2016).

Nalgonda technique, being a batch process, suffers from a limitation in terms of the amount of water being treated. Another limitation of the technique is the high amount of residual aluminium left in the treated water, which is due to high concentration of suspended solids that primarilly comprise alumino-fluoro complexes not being able to settle under plain sedimentation (Dubey et al., 2018). We expected that shifting the process to continuous mode may enhance the treatment capacity significantly and it would be able to serve relatively larger communities. Shifting of the system to continuous mode had the risk to result in increase in the treated water turbidity as the settle ability suffers in such systems compared to the batch mode. It was further perceived that the low turbidity of the raw groundwater may not permit efficient sweep floc mechanism, the major mode of action of alum, resulting in high concentration of suspensions of alumino-fluoro complexes. Thus the present study focuses on the use of Polyaluminium chloride $(80 \%$ and $100 \%$ doses), which promotes bridging action for the removal of suspensions and hence expected to work well at low raw water turbidity levels. Aluminium salts such as alum, poly aluminium chlorides etc. are widely used as coagulants for the removal of organic and inorganic pollutants in water and wastewater [20]. Poly Aluminium Chloride (PACl) can be an effective coagulant for

\footnotetext{
* Corresponding Author: madhunaresh@gmail.com
} 
the removal of fluoride from water with higher removal efficiency (Sharma et al., 2015) . It was reported by George et al. (2010) that despite close controls exercised in laboratory conditions, the Nalgonda process cannot meet the standards for residual aluminium in drinking water and the majority of aluminium remains in colloidal suspensions, which required filtration through a 0.2 micron filter to meet the above requirement (Dubey et al., 2017a). The present study shows the experimental results of both batch and continuous mode Nalgonda process with a subsequent step of filtration through 0.2 micron filter.

\section{Material and Methods}

\subsection{Chemicals}

All chemicals used for the study, namely, sodium fluoride $(\mathrm{NaF})$, aluminium sulphate $\left(\mathrm{Al}_{2}\left(\mathrm{SO}_{4}\right)_{3} \cdot 16 \mathrm{H}_{2} \mathrm{O}\right)$, lime were of analytical grade obtained from Merck. Polyaluminium chloride solution (KANPAC 10 HB) was obtained from Aditya Birla group, with Aluminium content of $10.2 \%$ as $\mathrm{Al}_{2} \mathrm{O}_{3}$ as per the specifications provided by the supplier.

\section{Analytical Methods}

The residual ûuoride in treated water was analyzed using fluoride ion selective electrode (Orion Star A 214) and coupled to a standard electrode as reference. The residual aluminium content in the treated samples was determined by Atomic Absorption Spectroscopy (LABINDIA Analytical AA8000).

\subsection{Batch Study for fluoride removal}

Batch experiments were carried out on conventional Nalgonda process for varying raw water fluoride concentrations at recommended doses of alum $(80 \% \& 100 \%)$ and equivalent PACl $(80 \% \& 100 \%)$ in terms of aluminium. The $1000 \mathrm{ml}$ of known fluoride concentration solution was taken in a beaker and dose of alum/PACl and lime was added to it as per the specifications of Nalgonda process. The content of beaker was then flash mixed at 100-130 rpm for initial 10 minutes followed by slow stirring at 7-10 rpm for 20 minutes. After the settlement for $30 \mathrm{~min}$, the supernatant was analyzed for residual fluoride and aluminum. Treated water was analyzed for various parameters to derive the efficiency of fluoride removal and its quality was also assessed in terms of residual aluminium.

\subsection{Continuous flow Nalgonda Process}

In order to increase the throughput of the process, a defluoridation set-up was fabricated for carrying out the Nalgonda defluoridation experiments in continuous mode as shown in figure 1. Alum/PACl and lime solutions of specific concentrations were added to designated tanks to deliver the doses prescribed in the Nalgonda defluoridation table given by Nawlakhe et al. (1975). The flow rate of the chemicals was maintained using the peristaltic pump. The dosage of $\mathrm{PACl}$ was kept equivalent to that of alum in terms of aluminium. Apart from equivalent doses, another set of experiments with lower dose at $80 \%$ of the aforementioned prescribed doses was also run in order to determine the optimum dose for fluoride removal. Lime was added to maintain a desirable $\mathrm{pH}(6.5-8.5)$ for floc formation. Being relatively less acidic, the PACl required half of the amount of lime as that for alum for $\mathrm{pH}$ maintenance.

\section{Results and Discussion}

\subsection{Defluoridation efficiency}

In the conventional batch Nalgonda process, treatment with recommended doses as per Nawlakhe et al. (1975) as well as $80 \%$ of these recommended doses of alum and lime resulted in acceptable levels of $1.5 \mathrm{mg} / \mathrm{L}$ of residual fluoride in the water as depicted in figure 2

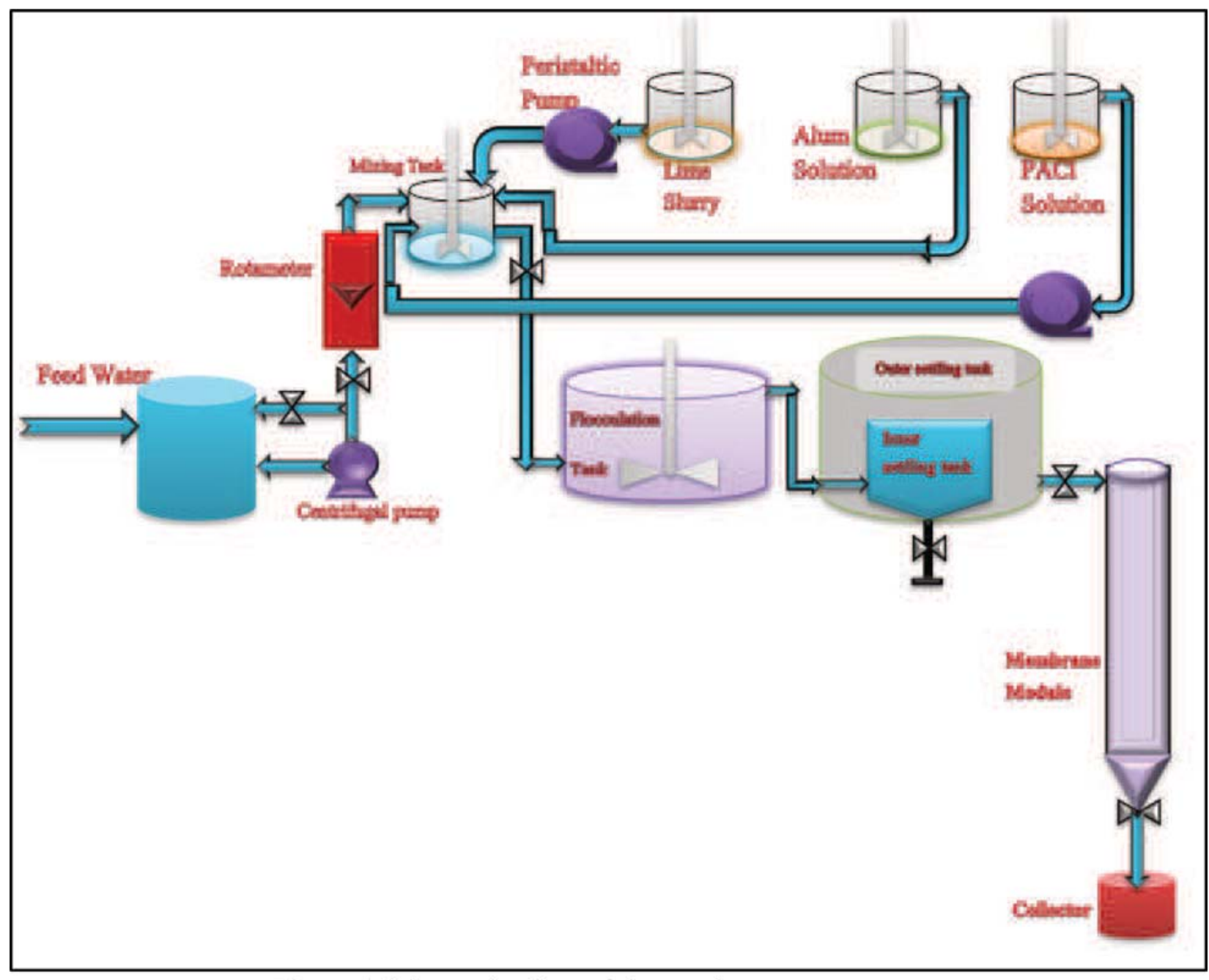

Figure 1 Schematic view of the continuous setup 
respectively which indicate almost comparable performance of the two systems in terms of fluoride removal though alum appeared to have a slight edge over PACl (Nawlakhe \& Bulusu, 1989). In order to increase

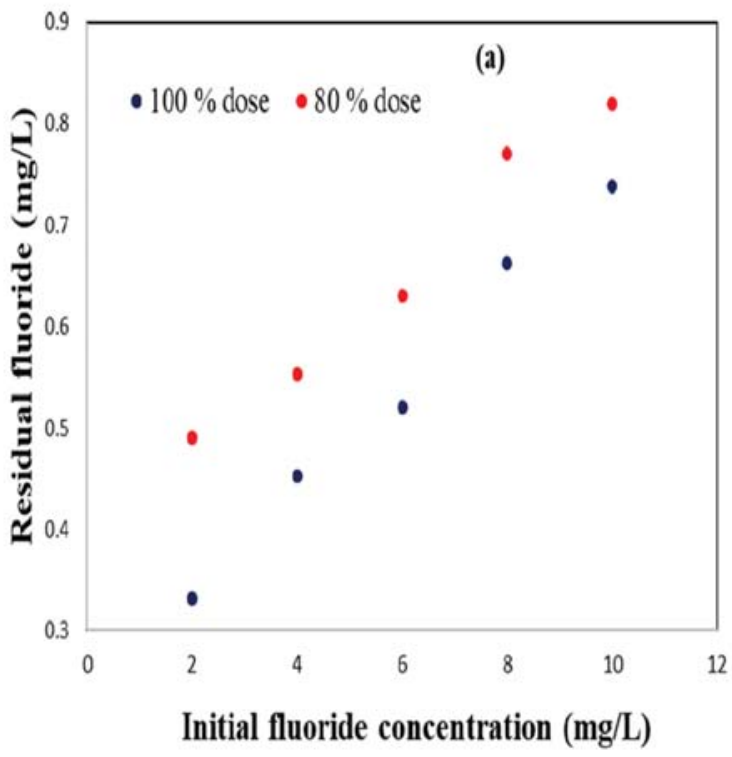

the throughput of the process, a defluoridation set-up was fabricated for carrying out the Nalgonda defluoridation experiments in continuous mode and the results are shown in figure 3.

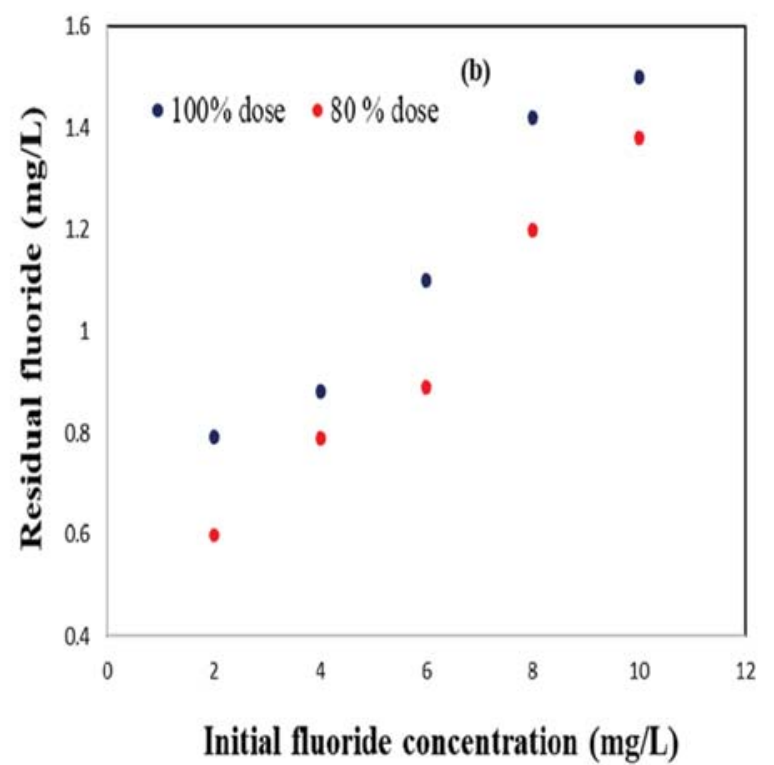

Figure 2 Comparative fluoride removal efficiency of (a) alum and (b) $\mathrm{PACl}$ at $80 \%$ and $100 \%$ doses in batch mode
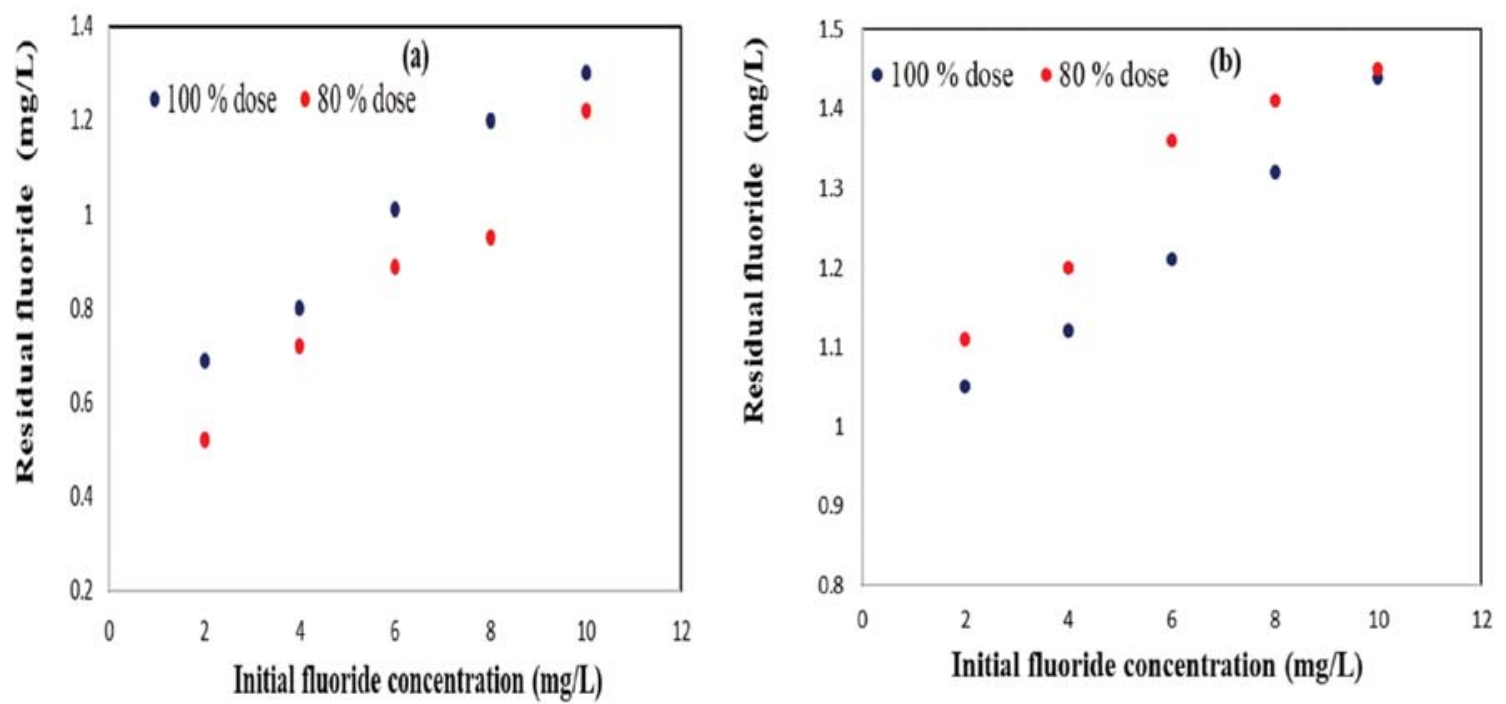

Figure 3 Comparative fluoride removal efficiency of (a) alum and (b) $\mathrm{PACl}$ at $80 \%$ and $100 \%$ doses in continuous mode Figure 4 Total \& dissolved fluoride of (a) alum and (b) $\mathrm{PACl}$ at $80 \%$ and $100 \%$ doses

From the results, it can be observed that residual fluoride was less for $80 \%$ doses than for $100 \%$ dose. Both alum and $\mathrm{PACl}$ were efficient for defluoridation at $80 \%$ as well as $100 \%$ dose, indicating that the Nalgonda process recommends higher dose of chemicals than what is actually required stoichiometrically for defluoridation. Parthasarathy \& Buffle 1986 reported that monomeric Al species react almost instantaneously with fluoride ions and polymeric species act much more slowly (Parthasarathy \& Buffle, 1985). The polymeric aluminium hydroxides $\mathrm{Al}(\mathrm{OH})_{33}{ }^{0}$ serve as sites for complexation of fluoride in the fluoride removal mechanism (Dubey et al., 2017b; Gong et al., 2012). These precipitating aluminium hydroxides $\mathrm{Al}_{\mathrm{n}}(\mathrm{OH})_{3 \mathrm{n}}{ }^{0}$ acquire charges by adsorbing and desorbing $\mathrm{H}^{+}$ions and form positively and negatively charged particles depending upon the $\mathrm{pH}$ of the aqueous medium $\left(\mathrm{pH}_{\mathrm{pzc}}\right.$ in 7.5 to $8.5 \mathrm{pH}$ range) (Liu et al., 2013). At lower $\mathrm{pH}$ all surface hydroxyl groups are positively charged in protonated form and electrostatic interactions are responsible for surface adsorption of negatively charged ions on to the hydroxide particle (Vuèina-Vujoviæ et al., 2003). Both these chemicals follow the aforementioned basic mechanism for defluoridation and hence were expected to produce similar results (Yang et al., 2010). However, the marginal difference in residual fluoride was perceived due to difference in turbidity resulting from suspensions of alumino-fluoro complexes, which may have different settling properties as the mechanism for their removal would be different as explained in the subsequent section (Agarwal et al., 2017; Wang et al., 2002). This was further expected to result in differences in residual aluminium in the two systems (Yan et al., 2008). To assess the above hypothesis, suspensions were dissolved with $\mathrm{HNO}_{3}$ and the samples were re-analyzed for total residual fluoride. The results are shown in figure 4. 

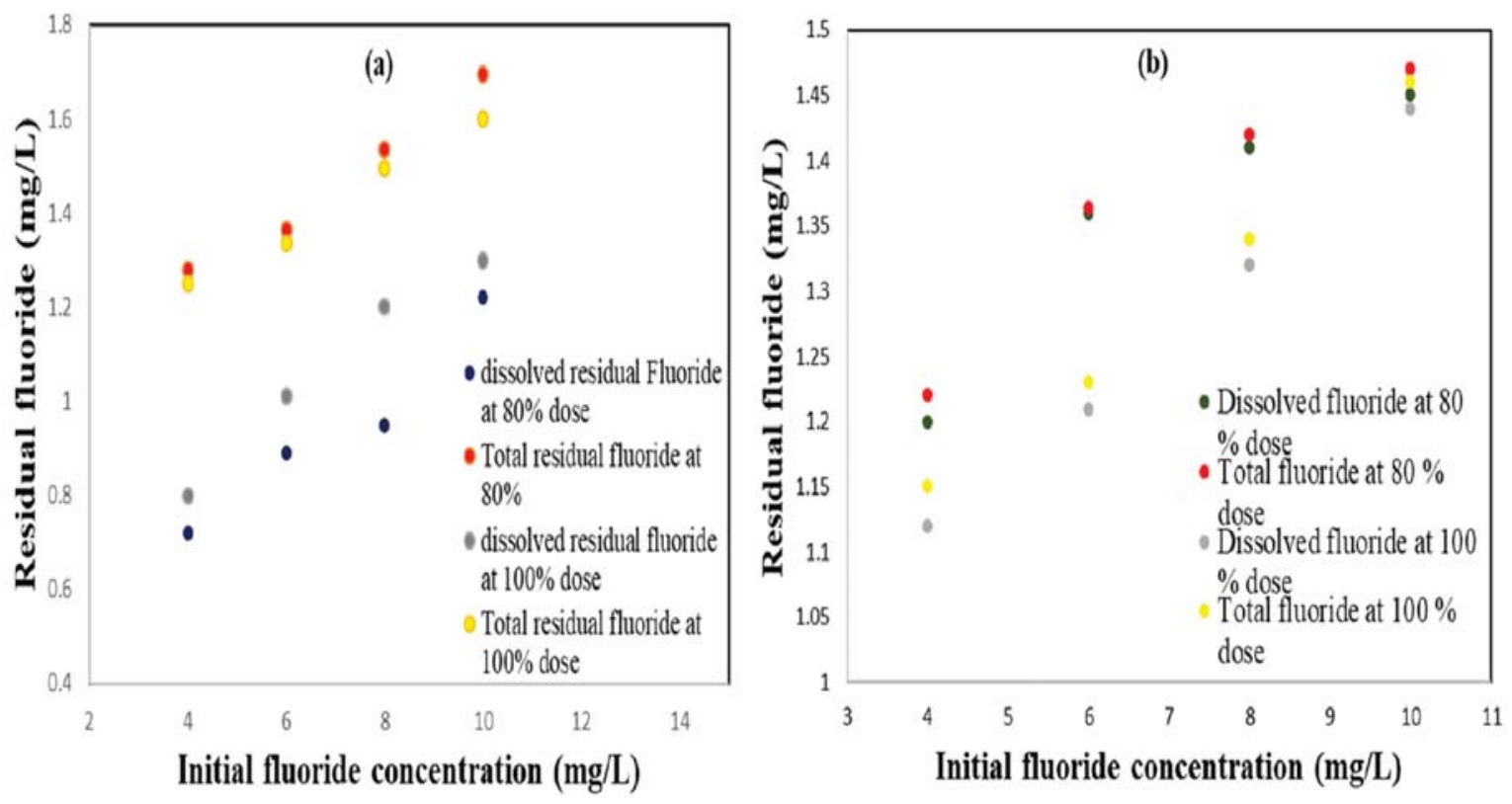

Figure 4 Total \& dissolved fluoride of (a) alum and (b) PACl at $80 \%$ and $100 \%$ doses

From figure 4, it can be seen that $\mathrm{PACl}$ has comparable fluoride removal efficiency to alum at both $100 \%$ as well as $80 \%$ of the recommended doses. The residual fluoride is within the acceptable limit $(<1.5 \mathrm{mg} / \mathrm{L})$ for drinking water on treatment with either alum or PACl. It can be also seen that the fluoride removal is better at higher initial concentrations of fluoride in raw water (Aoudj et al., 2012; Kumbhar \& Salkar, 2014). The residual turbidity was a cause of high concern as this comprised predominantly alumino-fluoro complexes, which may induce high residual $\mathrm{Al}$ in treated water, thus a filtration step was added in sequence (Muthu et al., 2003). More fluoride was found in suspension form in water treated with alum due to high turbidity (Jiao et al., 2015).

\subsection{Membrane Filtration}

The samples were filtered using microfiltration membrane having 0.2 micron pore size. Vacuum was applied while filtering the samples through 0.2 micron pore size microfiltration membrane. Table 1 shows that the samples with initial fluoride concentration of $4 \mathrm{mg} / \mathrm{L}$ which were treated with $\mathrm{PACl}$ and showed better results through the membrane as compared to those treated with alum (Wu et al., 2007; Yan et al., 2008). This can be attributed to the fact that $\mathrm{PACl}$ treated samples are less turbid due to fewer suspensions as compared to those produced by alum (Tang et al., 2015). This gives the advantage of introducing lesser load on the membrane which in turn will lead to increased life of the membrane and less frequency of cleaning of the membrane (Xu \& Gao, 2012).
The aluminium $\mathrm{Al}^{3+}$ ions that occur in their hydrated form in water have a primary hydration shell with six octahedrally coordinated water molecules, e.g. $\mathrm{Al}\left(\mathrm{H}_{2} \mathrm{O}\right)_{63}{ }^{+}$(Dubey et al., 2017b). Hem \& Roberson 1967 described the behavior of aluminium hydroxide precipitates during the hydrolysis mechanism with respect to varying $\mathrm{pH}$ of the aqueous solution (Hem \& Roberson, 1967). The acceptable limit of aluminium in drinking water is $0.2 \mathrm{mg} / \mathrm{L}$ (Gorchev \& Ozolins, 2017). Since Nalgonda technique uses aluminium sulphate for fluoride removal, so a part of the dose used remains in the water in dissolved form and also in suspension with fluoride in the form of flocs (Jagtap et al., 2012). So, membrane filtration is necessary to remove these suspensions (Xu \& Gao, 2012).

Without filtration the content was much beyond the acceptable limit, but after filtration through $0.2 \mu \mathrm{m}$ pore size microfiltration membrane, the residual aluminium contents are within the acceptable limit $(0.2 \mathrm{mg} /$ L) for aluminium in drinking water. This establishes that microfiltration is sufficient to reduce the residual aluminium content to acceptable limits in treated samples after treatment with either alum or PACl.

\section{Conclusion}

In the present study, attempt has been made to apply reduced amount of alum \& $\mathrm{PACl}$ dose (i.e. $80 \%$ of the recommended dose) to observe the effect on fluoride removal. In case of alum, for initial fluoride concentration of $10 \mathrm{mg} / \mathrm{L}$, the residual fluoride concentration was $0.738 \mathrm{mg} / \mathrm{L}$ (batch) \& $1.22 \mathrm{mg} / \mathrm{L}$ (continuous) at $80 \%$ dose and at $100 \%$ dose it was 0.82

Table 1 Residual aluminium for initial fluoride concentration of $4 \mathrm{mg} / \mathrm{L}$ in batch mode

\begin{tabular}{llll}
\hline S. No. & Treating Agent & Sample Detail & Aluminium \\
& & & content $(\mathbf{m g} / \mathbf{L})$ \\
\hline 1. & Alum & Before filtration & 0.46 \\
2. & Alum & After filtration through & 0.182 \\
3. & PACl & Before filtration & \\
4. & PACl & After filtration & 0.34 \\
& & through 0.2 membrane & 0.143
\end{tabular}


$\mathrm{mg} / \mathrm{L}$ (batch) \& $1.33 \mathrm{mg} / \mathrm{L}$ (continuous). In case of $\mathrm{PACl}$, for initial fluoride concentration of $10 \mathrm{mg} / \mathrm{L}$, the residual fluoride concentration was $1.33 \mathrm{mg} / \mathrm{L}$ (batch) \& $1.45 \mathrm{mg} / \mathrm{L}$ (continuous) at $80 \%$ dose and at $100 \%$ dose it was $1.5 \mathrm{mg} / \mathrm{L}$ (batch) \& $1.44 \mathrm{mg} / \mathrm{L}$ (continuous). With the subsequent microfiltration, residual aluminium was found to be 0.182 $\mathrm{mg} / \mathrm{L}$ (alum) and $0.143 \mathrm{mg} / \mathrm{L}(\mathrm{PACl})$ for initial fluoride concentration of $4 \mathrm{mg} / \mathrm{L}$. It was also found that $\mathrm{PACl}$ required almost half of the dose of lime for $\mathrm{pH}$ adjustment for floc formation.

\section{References}

[1] Aoudj, S., Drouiche, N., Hecini, M., Ouslimane, T., \& Palaouane, B. (2012) Coagulation as a post-treatment method for the defluoridation of photovoltaic cell manufacturing wastewater. Procedia Engineering, 33, 111-120.

[2] Dubey, S., Agarwal, M., \& Gupta, A. B. (2017a) A study on the characterisation of the species formed during fluoride removal through coagulation, Interdiscip. Environ. Rev., 18, 143-154.

[3] Agarwal, M., Dubey, S. \& Gupta, A. B. (2017) Coagulation process for fluoride removal by comparative evaluation of Alum \& PACl coagulants with subsequent membrane microfiltration, Int. J. Environ. Technol. Manag., 20, 201-224.

[4] Dubey, S., Agarwal, M., \& Gupta, A. B. (2017b) Electrospray Ionization Time-ofFlight Mass Spectrum Analysis Method of Products Formed after Coagulation with Aluminium Sulphate, Int. J. Eng. Technol. Manag. Appl. Sci., 5, 582-587.

[5] Dubey, S., Agarwal, M., \& Gupta, A. B. (2018) Recent Developments In Defluoridation Of Drinking Water In India. In V. P. Singh, S. Yadav, \& R. N. Yadava (Eds.), Environmental Pollution (pp. 310-322). Springer International Publishing.

[6] Dubey, S., Agarwal, M., Gupta, A. B., Dohare, R. K., \& Upadhyaya, S. (2016) Automation Control in Defluoridation Water Treatment Plant, Int. J. Adv. Technol. Eng. Explor., 4, 6-11.

[7] Gong, W.X., Qu, J.H., Liu, R.P., Lan, H.C. (2012) Effect of aluminum fluoride complexation on fluoride removal by coagulation. Colloids Surfaces A Physicochem. Eng. Asp., 395 , 88-93.

[8] Gorchev, H. G., \& Ozolins, G. (2011) WHO guidelines for drinking-water quality. WHO Chron., 38, 104-108.

[9] Gorchev, H. G., \& Ozolins, G. (2017) WHO guidelines for drinking-water quality: fourth edition incorporating the first addendum.

[10] He, Z., Lan, H., Gong, W., Liu, R., Gao, Y., Liu, H., \& Qu, J. (2016) Coagulation behaviors of aluminum salts towards fluoride: Significance of aluminum speciation and transformation, Sep. Purif. Technol., 165, 137-144.

[11] Hem, J. D., \& Roberson, C. E. (1967) Form and Stability of Aluminum Hydroxide Complexes in Dilute Solution. USGS Water Supply Paper, 1827-A, 55.

[12] Hu, C. Y., Lo, S. L., \& Kuan, W. H. (2003) Effects of co-existing anions on fluoride removal in electrocoagulation (EC) process using aluminum electrodes. Water Res., 37, 4513-4523.

[13] Jagtap, S., Yenkie, M. K., Labhsetwar, N., \& Rayalu, S. (2012) Fluoride in drinking water and defluoridation of water. Chemical Reviews, 112, 2454-2466.

[14] Jiao, R., Xu, H., Xu, W., Yang, X., \& Wang, D. (2015) Influence of coagulation mechanisms on the residual aluminum - The roles of coagulant species and MW of organic matter. Journal of Hazardous Materials, 290, 16-25.

[15] Kaseva, M. E. (2006) Optimization of regenerated bone char for fluoride removal in drinking water: A case study in Tanzania, J. Water Health, 4, 139-147.

[16] Kumbhar, V. S., \& Salkar, V. D. (2014) Use of PAC as a Substitute for Alum in Nalgonda Technique, 4, 154-161.

[17] Liu, R., Zhu, L., Gong, W., Lan, H., Liu, H., \& Qu, J. (2013) Effects of fluoride on coagulation performance of aluminum chloride towards Kaolin suspension. Colloids and Surfaces A: Physicochemical and Engineering Aspects, 421, 84-90.

[18] Muthu, G. I., Vinodhini, V., \& Padmapriya, G. Sathiyanarayanan, K. Sabumon, P. C. (2003) An improved method for defluoridation, Indian J. Environ. Health, 45, 6572.

[19] Nawlakhe, W. G., \& Bulusu, K. R. (1989) Nalgonda technique - a process for removal of fluoride from drinking water, Water Qual. Bull., 14, 218-220.

[20] Nawlakhe, W. G., Kulkarni, D. N., Pathak, B. N., \& Bulusu, K. R. (1975) Defluoridation of water by Nalgonda Technique, Indian J. Environ. Health, 17, 26-65.

[21] Parthasarathy, N., \& Buffle, J. (1985) Study of polymeric aluminium(III) hydroxide solutions for application in waste water treatment. Properties of the polymer and optimal conditions of preparation, Water Res., 19, 25-36.

[22] Parthasarathy, N., \& Buffle, J. (1986) Study of interaction of polymeric aluminium hydroxide with fluoride, Fluoride, 64, 24-29.

[23] Sharma, P., Agarwal, M., \& Gupta, A. B. (2015) Polyaluminium Chloride- An Alternative to Alum for Defluoridation, Int. J. Adv. Res. Sci. Eng., 4, 323-327.

[24] Tang, H., Xiao, F., \& Wang, D. (2015) Speciation, stability, and coagulation mechanisms of hydroxyl aluminum clusters formed by PACl and alum: A critical review. Advances in Colloid and Interface Science, 226, 78-85.

[25] Vuèina-Vujoviæ, A. J., Jankoviæ, I. A., Milonjiæ, S. K., \& Nedeljkoviæ, J. M. (2003) Influence of $\mathrm{AlOOH}$ nanoparticles on the oxidation of iodide by persulphate, Colloids Surfaces A Physicochem. Eng. Asp., 223, 295-300.

[26] Waghmare, S. S., \& Arfin, T. (2015) Fluoride Removal By Industrial, Agricultura and Biomass Wastes As Adsorbents/ : Review, Int. J. Adv. Res. Innov. Ideas Educ. 1, 628-653.

[27] Wang, G.-S., Kang, S.-F., Yang, H.-J., Pai, S.-Y., \& Chen, H.-W. (2002) Removal of Dissolved Natural Organic Matter from Source Water with Alum Coagulation. Environmental Technology, 23, 1415-1423.

[28] Wu, X., Ge, X., Wang, D., \& Tang, H. (2007). Distinct coagulation mechanism and model between alum and high $\mathrm{Al}_{13}-\mathrm{PACl}, 305,89-96$.

[29] Xu, W., \& Gao, B. (2012) Effect of shear conditions on floc properties and membrane fouling in coagulation/ultrafiltration hybrid process-The significance of $\mathrm{Al} \mathrm{b}$ species. Journal of Membrane Science, 415-416, 153-160.

[30] Yan, M., Wang, D., Ni, J., Qu, J., Chow, C. W. K., \& Liu, H.(2008) Mechanism of natural organic matter removal by polyaluminum chloride: Effect of coagulant particle size and hydrolysis kinetics. Water Research, 42, 3361-3370.

[31] Yang, Z., Gao, B., \& Yue, Q. (2010) Coagulation performance and residual aluminum speciation of $\mathrm{Al}_{2}(\mathrm{SO})_{3}$ and polyaluminum chloride (PAC) in Yellow River water treatment. Chemical Engineering Journal, 165, 122-132. 